\title{
Variability of Data in High Throughput Experimentation for Catalyst Studies in Fuel Processing
}

\author{
N.T.J. Luchters ${ }^{1 *}$, J.V. Fletcher ${ }^{1}$, S.J. Roberts ${ }^{2}$, J.C.Q. Fletcher ${ }^{2}$ \\ ${ }^{1}$ HySA/Catalysis Centre of Competence, University of Cape Town, \\ Private Bag X3, Rondebosch 7701, South Africa \\ ${ }^{2}$ Centre for Catalysis Research, Department of Chemical Engineering, University of Cape Town, \\ Private Bag X3, Rondebosch 7701, South Africa
}

Received: 23 $3^{\text {rd }}$ September 2016; Revised: $18^{\text {th }}$ November 2016; Accepted: $22^{\text {nd }}$ November 2016

\begin{abstract}
The use of high throughout and combinatorial experimentation is becoming commonplace in catalytic research. The benefits of parallel experiments are not only limited to reducing the time-to-market, but also give an opportunity to study processes in more depth, by generating more data. To investigate the complete parameter space, multiple experiments must be performed and the variability between these experiments must be quantifiable. In this project, the reproducibility and variance in high throughput catalyst preparation and parallel testing were determined. High-performance equipment was used in a catalyst development program for fuel processing, the production of fuel cell-grade hydrogen from hydrocarbon fuels. Four studies, involving water-gas shift conversion and high-temperature steam methane reforming, were performed to determine the reproducibility of the workflow from automated catalyst preparation to parallel activity testing. Statistical analyses showed the standard deviation in catalytic activities as determined by conversion, to be less than $6 \%$ of the average value. Copyright (C) 2017 BCREC GROUP. All rights reserved
\end{abstract}

Keywords: High throughput; Fuel processing; Steam methane reforming; Water-Gas shift; Hydrogen production; Reproducibility

How to Cite: Luchters, N.T.J., Fletcher, J.V., Roberts, S.J., Fletcher, J.C.Q. (2017). Variability of Data in High Throughput Experimentation for Catalyst Studies in Fuel Processing. Bulletin of Chemical Reaction Engineering \& Catalysis, 12 (1): 106-112 (doi:10.9767/bcrec.12.1.708.106-112)

Permalink/DOI: http://dx.doi.org/10.9767/bcrec.12.1.708.106-112

\section{Introduction}

Fossil fuels supply about $85 \%$ of the total world energy requirements [1]. With more governments planning to implement a 'carbon tax' on the production of $\mathrm{CO}_{2}$, the use of alternative energy sources is becoming increasingly attractive. Alternative energy sources do however have their own advantages and disadvantages (economic, environmental and social impact)

\footnotetext{
* Corresponding Author.

E-mail: niels.luchters@uct.ac.za (Luchters, N.T.J.)

Telp.: +27(0)216505760
}

making their implementation very much dependent on local factors.

Hydrogen is the fuel of choice for most stationary and mobile fuel cells, a promising technology for generating electricity with high fuel efficiency [2]. This brings solutions as a power source for vehicles [3] as well as back-up power and off-grid electricity generation. More specifically, fuel cells have the potential to supply electricity with high efficiency to remote locations where the capital costs involved in extending the electrical grid are very high. The lack of a proper hydrogen infrastructure (production, storage, distribution), however, 
limits the implementation of fuel cells in these remote locations.

Natural resources from which hydrogen can be extracted include water, fossil fuels (hydrocarbons) and biomass. It is anticipated that, in the long-term, hydrogen will be generated via carbon-free technology (renewable resources), such as solar photovoltaic and electrolysers. The current "carbon free" technologies, however, remain too expensive and efficiency needs to be improved [1]. In the transition period to a carbon-free renewable hydrogen economy, reforming of fossil fuels should be considered as practical hydrogen source using widely available fuels and existing infrastructure [4].

Fuel processing is an attractive technology to convert fossil fuels (like natural gas, LPG, diesel, jet fuels, etc.) into hydrogen or syngas. Utilising the existing global infrastructure for these fuels, hydrogen can be produced on-site and, after clean-up, can be used to directly feed fuel cells [5]. Consequently, the availability of catalytic fuel processors are an important requirement for the widespread (near to middle term) implementation of fuel cells [6].

The catalysts used in fuel processors have demanding requirements with respect to lifetime, stability and ease of start-up, where long reduction procedures and temperature sensitive formulations are unsuitable. Research aimed at the development of suitable fuel processing catalysts is predominantly based on platinum group metals, an active field of enquiry.

Traditionally, catalyst development involves a one-at-a-time sequence of preparation and performance testing. However, the exploitation of massively parallelized experimentation, socalled high throughput experimentation, is gaining increasing acceptance as a vehicle for the discovery, development and optimisation of new catalytic systems $[7,8]$. Currently several commercial, state-of-the-art technologies exist for catalyst preparation, catalyst testing and the associated handling of vast data sets [8].

The terms "high throughput experimentation" and "combinatorial screening" are often still interchangeably applied [9]. Even IUPAC defines high throughput screening as the "process for rapid assessment of the activity of samples from a combinatorial library or other compound collection, often by running parallel assays in plates of 96 or more wells" [10], the definition mostly focussing on pharmaceutical research. Maier et al. redefined the terms for the material sciences and chemical industry, such that the term refers to a change in the nature of the parameters, not to a change in the value of the parameter. The systematic change of parameters, like composition, temperature, pressure, etc., to explore a wide parameter space is defined as high throughput experimentation [7]. Typically, both approaches make use of parallelization: performing multiple experiments in parallel, under similar conditions, with variation in the studied parameter. In this paper, the term high throughput experimentation refers to parallel experiments, as both the catalyst formulations and experimental condition play an important role in catalyst optimization. Experiments are often interchanged between combinatorial and high throughput, although, experimental procedures are similar.

High throughput experimentation has been applied since the early twentieth century with Edison (1878), Ciamician (1912), and the development of the catalyst for ammonia synthesis by Mitasch at BASF in 1909 [7]. Despite this long history, only in the late 1990s did the methodology commercialize, partly favoured by the technology-friendly venture capital boom. Commercial enterprises focusing specifically on high throughput experimentation such as SYMYX, Chemspeed, hte, and Avantium found their way to the market [8]. Although in research circles much scepticism still surrounds this approach, it is slowly gaining acceptance.

This paper seeks to establish the consistency of results from high throughput experimentation in automated catalyst preparation and the subsequent testing thereof in parallel reactors. For this case study, the reactions considered are the first two stages of a typical fuel processor i.e. high temperature methane steam reforming and water-gas shift, both stages employing platinum group metal catalyst formulations. For each study, catalysts were prepared on the Chemspeed ISYNTH platform and the consistency in formulation was investigated through characterisation techniques (ICP and CO chemisorption analysis). The catalytic performance was determined using an Avantium 16 parallel reactor setup in two types of experiments, viz, a) all reactors containing a single prepared catalyst - referred to here as one-to-many (one catalyst in many reactors), and b) eight repeat formulations tested in parallel - referred to as a many-to-many experiment (see Figure 1).

\section{Materials and Methods}

\subsection{Catalysts preparation}

Catalysts were prepared using the Chemspeed ISYNTH synthesis robot, employing a 
recipe for incipient wetness impregnation. Two series of catalysts were prepared; one comprising of 8 catalyst batches of $1 \mathrm{wt} \% \mathrm{Pt} / \mathrm{Al}_{2} \mathrm{O}_{3}$ and a second of 8 catalyst batches of $0.5 \mathrm{wt} \%$ $\mathrm{Rh} / \mathrm{Al}_{2} \mathrm{O}_{3}$ - in both cases the support being $\mathrm{Pu}$ ralox alumina NWA-155. Stock solutions of chloroplatinic acid or rhodium nitrate (SigmaAldrich) of sufficient concentration, so as to ultimately prepare catalysts with the desired metal loading, were prepared by dissolving appropriate amounts of metal salts in de-ionised water. These stock solutions were subsequently further diluted by the Chemspeed ISYNTH robot as required for each impregnation. The catalysts were prepared by addition of $1.4 \mathrm{ml}$ PGM impregnation solution to $2 \mathrm{~g}$ of support via a fine injection needle, whilst under continuous agitation. Thereafter, the catalysts were evacuated to 500 mbar and dried at $30{ }^{\circ} \mathrm{C}$ for 1 hour under continuous vigorous agitation to ensure good mixing and contact between support and impregnation solution. Subsequent treatments involved drying as follows: 2 hours at atmospheric pressure and $60{ }^{\circ} \mathrm{C}$, followed by 4 hours at $120^{\circ} \mathrm{C}$ and, finally, calcination for 5 hours at $500{ }^{\circ} \mathrm{C}$ (for WGS catalysts) or $800{ }^{\circ} \mathrm{C}$ (for reforming catalysts) in static air. During drying steps, the temperature was ramped at $1{ }^{\circ} \mathrm{C} / \mathrm{min}$.

\subsection{Catalyst characterization}

CO chemisorption was performed on the $1 \mathrm{wt} \% \mathrm{Pt} / \mathrm{Al}_{2} \mathrm{O}_{3}$ catalyst series in a Micromeritics ASAP 2000 apparatus equipped with two Edwards vacuum pumps (E2M-0.7). The sample (in powder form) was heated to $250{ }^{\circ} \mathrm{C}$ at a rate of $5{ }^{\circ} \mathrm{C} / \mathrm{min}$ in flowing $\mathrm{H}_{2}$ to remove adsorbed water and reduce any platinum oxide to $\mathrm{Pt}$ metal. The sample was maintained at $250{ }^{\circ} \mathrm{C}$ for one hour, after which the $\mathrm{H}_{2}$ flow was stopped and the sample chamber evacu-

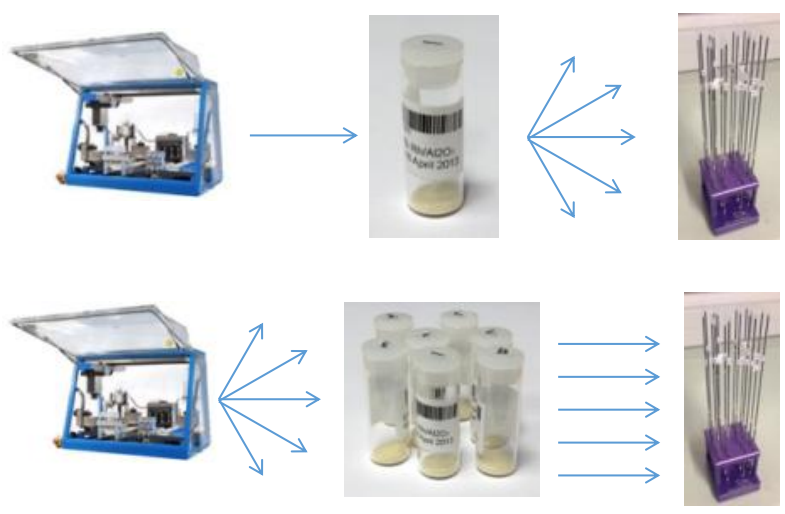

Figure 1. Experimental setups; top one-tomany, bottom many-to-many ated for 2 hours, attaining a pressure of $10^{-3} \mathrm{~mm} \mathrm{Hg}$. The temperature was subsequently lowered to room temperature at $5{ }^{\circ} \mathrm{C} / \mathrm{min}$, and $\mathrm{CO}$ chemisorption was performed. A Varian 730 ICP-OES (inductively coupled plasma - optical emission spectrometer) instrument was used to determine the metal content of fresh (unused) catalysts. The sample was digested with a mixture of hydrochloric, hydrofluoric and nitric acids in a MARS-5 microwave digester, followed by neutralization with boric acid prior to analysis.

\subsection{Catalyst testing}

Catalyst testing was performed on a Flowrence, 16 parallel fixed-bed reactor (stainless steel for WGS or quartz for SMR) instrument from Avantium. A gas feed composition was mixed by mass flow controllers and distributed to each reactor by equal pressure drop using capillaries. Steam was fed as liquid water by a HPLC pump and distributed by capillaries to each reactor. Evaporation of water occurred at the top of the reactor before reaching the catalyst bed. The catalysts were activated in-situ using a $\mathrm{H}_{2} / \mathrm{N}_{2}$ mixture (10 vol\% $\mathrm{H}_{2}$ for WGS; 100 vol\% $\mathrm{H}_{2}$ for SMR) and heated to 204,300 and $750{ }^{\circ} \mathrm{C}$ for the commercial low temperature shift (LTS), $\mathrm{Pt} / \mathrm{Al}_{2} \mathrm{O}_{3}$ and $\mathrm{Rh} / \mathrm{Al}_{2} \mathrm{O}_{3}$ catalysts, respectively. Chromatographic analysis was performed using an Agilent CP490 micro-GC, with compounds separated over a MS5 or COX column and detected by a TCD. Methods on both columns were run isothermal and isobaric. A detailed overview of the analysis parameters is given in Table 1.

Four experiments were performed to determine the reproducibility of the high throughput catalyst testing. A commercial LTS catalyst as well as the Pt catalyst series were used for WGS at low and medium reaction tempera-
Table 1. Micro-GC parameters

\begin{tabular}{lcc}
\hline \multicolumn{1}{c}{ Channel \# } & 1 & 2 \\
\hline Column (length in meters) & MS5 & COX \\
& $(20 \mathrm{~m})$ & $(1 \mathrm{~m})$ \\
Injector temperature $\left({ }^{\circ} \mathrm{C}\right)$ & 109 & 109 \\
Column temperature $\left({ }^{\circ} \mathrm{C}\right)$ & 100 & 80 \\
Carrier gas & Argon & Helium \\
Carrier pressure $(\mathrm{kPa})$ & 250 & 110 \\
Sample line temperature $\left({ }^{\circ} \mathrm{C}\right)$ & \multicolumn{2}{c}{110} \\
Sample line flush time $(\mathrm{s})$ & \multicolumn{2}{c}{30} \\
Injection time $(\mathrm{ms})$ & 75 & 75 \\
Backflush timing $(\mathrm{s})$ & 11.5 & 8.5 \\
Analysis time $(\mathrm{min})$ & 5 & 5 \\
\hline
\end{tabular}


ture ranges, respectively. The commercial LTS catalyst was tested in a one-to-many experiment (one catalyst in 13 reactors), whereas the $\mathrm{Pt} / \mathrm{Al}_{2} \mathrm{O}_{3}$ catalyst series was tested in a manyto-many experiment (multiple catalyst batches prepared and each tested in a reactor). The steam methane reforming was evaluated at $700{ }^{\circ} \mathrm{C}$ in both one-to-many and many-to-many experiments using the $\mathrm{Rh} / \mathrm{Al}_{2} \mathrm{O}_{3}$ catalyst series.

To describe the reproducibility of a series of data points the standard deviation is calculated using Equation 1. For comparison purposes the standard deviation is expressed as a percentage of the average value (relative standard deviation; RSD).

$$
\text { Deviation Standard }=\sqrt{\frac{\sum(x-\bar{x})}{(n-1)}}
$$

\section{Results and Discussion}

\subsection{Variance in catalyst preparation}

ICP analysis for $\mathrm{Pt}$ metal loading on the $\mathrm{Pt} / \mathrm{Al}_{2} \mathrm{O}_{3}$ catalysts provides an indication of the accuracy of the impregnation volumes used. First, a duplicate measurement of seven ICP analyses on a single $\mathrm{Pt}$ batch resulted in a RSD of $4.8 \%$, a relatively low precision due to the low Pt loadings. Likewise, the Pt catalyst series exhibited a similar RSD for ICP metal loading (Table 2). However, the variance in the series of samples is not larger than the duplicate single batch measurement, implying that the deviation seen is mostly a result of the analysis technique rather than the impregnation.

The automated impregnation of the $\mathrm{Rh}$ series was also analyzed for $\mathrm{Rh}$ metal loading by ICP. A repeat of 6 analyses on a single catalyst batch yielded a RSD of $3.9 \%$, some what lower than for the Pt-containing samples. The analysis of the Rh catalyst series resulted in an average loading of $0.4 \pm 0.019 \mathrm{wt} \%(\mathrm{RSD}=4.7 \%)$. Although, the absolute Rh content in each catalyst was below the intended amount, the accuracy shows good reproducibility of impregnation by the synthesis robot.

The results from $\mathrm{CO}$ chemisorption of the $\mathrm{Pt} / \mathrm{Al}_{2} \mathrm{O}_{3}$ catalyst series ( 8 batches) are presented in Figure 2. Although, the metal dispersion and crystallite size are related to each other and calculated from the same analysis, the relative standard deviation on the series is $5.0 \%$ of the average.

\subsection{Water-gas shift}

Thirteen Avantium reactors were charged with a commercial LTS catalyst, with loadings between 75.9 and $77.6 \mathrm{mg}$. Given typical industrial conditions (20 barg, $200{ }^{\circ} \mathrm{C}, 40,000 \mathrm{~h}^{-1}$ ) a line-in period of approximately 4 days was observed (Figure 3). All catalysts behaved similarly. At approximately 100 hours on stream the average $\mathrm{CO}$ conversion was $38.8 \%$; the difference between the lowest and highest activity measured being 8 percentage points (RSD = $6.3 \%$ ). At approximately $110 \mathrm{~h}$ time on stream (TOS) the experiment was interrupted and reactor positions were changed around (reactor at position 14 was changed with reactor at position 16, etc.). After re-starting at $\sim 150$ hours TOS, a similar activity trend was observed with an equal spread between the reactors. It is therefore clear that the position of the reactor in the equipment does not influence the catalytic performance and the spread in activity between reactors is due to variation of catalyst mass in the different reactor tubes (i.e. small differences in catalyst loading).

The Chemspeed synthesis robot was used to prepare eight batches of $1 \mathrm{wt} \% \mathrm{Pt} / \mathrm{Al}_{2} \mathrm{O}_{3}$ catalyst. The catalytic performance of all eight batches was evaluated simultaneously in the Flowrence system for the WGS reaction at standard gas hourly space velocity (SGHSV) of 5,000, 10,000 and 15,000 $\mathrm{h}^{-1}$, and temperatures of 300,325 and $350^{\circ} \mathrm{C}$. This was done in order to measure variation in catalyst activity as a function of conversion (Figure 4).

The RSD at $\sim 50 \% \mathrm{CO}$ conversion is $4 \%$ of the average conversion. This is in accordance with the deviations found with the commercial catalyst. At lower conversions the RSD is found to be around $4 \%$, only increasing to $6.3 \%$ at very low CO conversions of approximately $11 \%$. The increase is ascribed to the chromatographic inaccuracy associated with the late elution of the CO peak on the MS5 column.

In the last step of the experiment, the conditions were reset to a SGHSV of $15,000 \mathrm{~h}^{-1}$ and temperature of $350{ }^{\circ} \mathrm{C}$ to verify if any catalyst deactivation had taken place (by comparison to a condition evaluated earlier in the test). The average conversion of $22.9 \%$ ( $\mathrm{ToS} \approx 200 \mathrm{~h}$ ) had decreased to $20 \%$ over a period of almost 100 hours and is not considered to have influenced the reproducibility estimations $(\sim 0.029$ percentage points per hour).

\subsection{Steam methane reforming}

Reproducibility of steam methane reforming catalysts were determined using a single catalyst batch, loaded into multiple reactors (oneto-many). More specifically, 12 quartz reactors were charged with an equal loading of $0.5 \mathrm{wt} \%$ 
$\mathrm{Rh} / \mathrm{Al}_{2} \mathrm{O}_{3}$ (catalyst mass per reactor between 50.1 and $50.9 \mathrm{mg}$ ) and methane conversions were measured. At start-up the SGHSV and temperature were set to $50,000 \mathrm{~h}^{-1}$ and $700{ }^{\circ} \mathrm{C}$ respectively, however, this resulted in conversions close to equilibrium, making true comparison of reactor-to-reactor activity variations difficult. Subsequently, the SGHSV was increased to $75,000 \mathrm{~h}^{-1}$ (at $\mathrm{ToS}=50 \mathrm{~h}$ ) and $120,000 \mathrm{~h}^{-1}$ (at ToS $=\sim 170 \mathrm{~h}$ ) to obtain conversion levels sufficiently removed from equilibrium, while maintaining the temperature at $700{ }^{\circ} \mathrm{C}$ (blue data points in Figure 5).

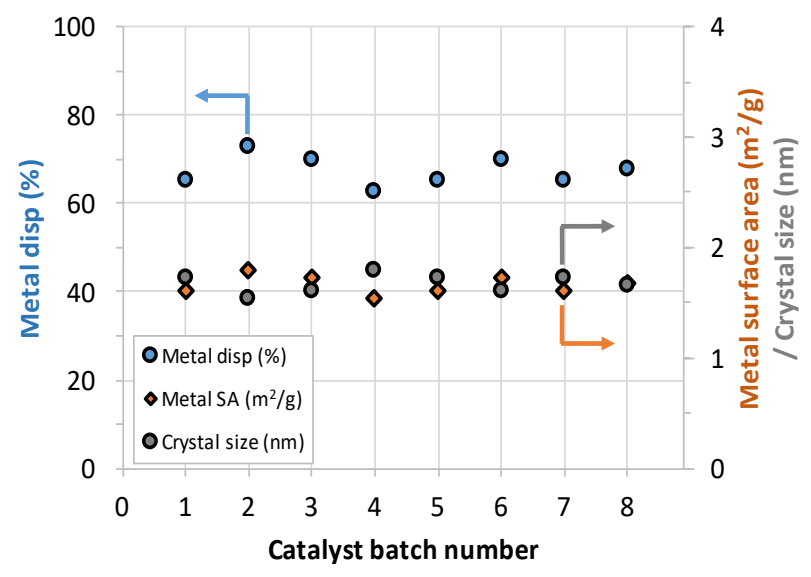

Figure 2. CO chemisorption analysis of $\mathrm{Pt} / \mathrm{Al}_{2} \mathrm{O}_{3}$ series

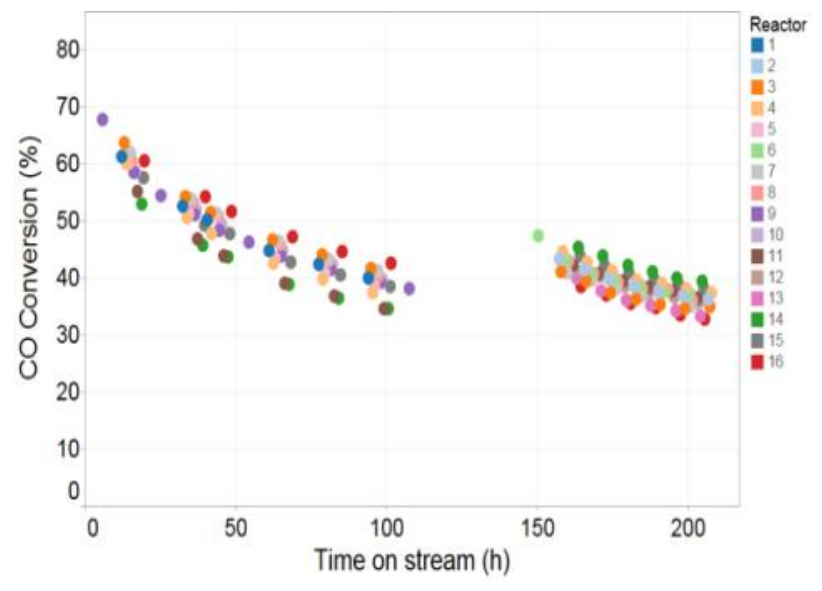

Figure 3. WGS CO conversions using commercial LTS catalyst
At $120,000 \mathrm{~h}^{-1}$ the average conversion decreased to $73 \%$ with a relative standard deviation of $2.7 \%$ (calculated on three analyses of all reactors). The data set, used for calculating the RSD, was considered to be at stable catalytic conditions, as the average conversion decreased only slightly (from 73 to $\sim 70 \%$ ) over the respective 150 hours on stream.

Eight batches of $0.5 \mathrm{wt} \% \mathrm{Rh} / \mathrm{Al}_{2} \mathrm{O}_{3}$ were prepared through incipient wetness impregnation using the Chemspeed. ICP analysis confirmed the average $\mathrm{Rh}$ loading to be $0.4 \pm 0.019 \mathrm{wt} \%$. The $\mathrm{Rh} / \mathrm{Al}_{2} \mathrm{O}_{3}$ catalysts were loaded into thirteen reactors (catalyst mass each reactor between 49.9 and $50.5 \mathrm{mg}$ ), making up the manyto-many reproducibility study. Activities were measured at SGHSV of $120,000 \mathrm{~h}^{-1}$ from the start of the experiment. The results show no initial line-in time required for the catalysts.

For the standard deviation calculations, three analyses of each reactor between 150 and 200 hours on stream were used. This corresponded to a similar dataset used in the one-tomany experiment. The RSD for the many-tomany experiment was $3.8 \%$ of the average methane conversion of $72.5 \%$ (i.e. $72.5 \pm 2.8 \%$ ).

The data for the one-to-many and many-tomany experiments were compared at the same SGHSV and ToS. In Figure 5 the blue data points are data for the one-to-many experiment at the three SGHSV $(50,000,75,000$, and

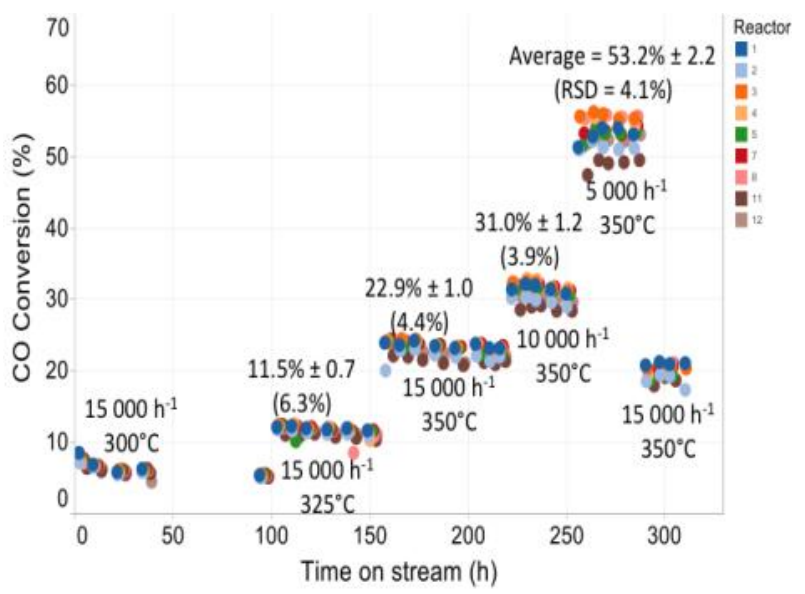

Figure 4. WGS CO conversion using 8 batches of $\mathrm{Pt} / \mathrm{Al}_{2} \mathrm{O}_{3}$

Table 2. ICP analysis of $\mathrm{Pt}$ and $\mathrm{Rh}$ catalysts

\begin{tabular}{ccccccccccc}
\hline Catalyst Batch & 1 & 2 & 3 & 4 & 5 & 6 & 7 & 8 & Average & RSD (\%) \\
\hline $\begin{array}{c}\mathrm{Pt} / \mathrm{Al}_{2} \mathrm{O}_{3} \\
\left(\mathrm{Pt} w \mathrm{w}_{0}\right)\end{array}$ & 1.07 & 1.05 & 1.12 & 1.06 & 1.02 & 1.05 & 1.08 & 0.99 & $1.06 \%$ & $3.7 \%$ \\
$\begin{array}{c}\mathrm{Rh} / \mathrm{Al}_{2} \mathrm{O}_{3} \\
(\mathrm{Rh} \mathrm{wt} \%)\end{array}$ & 0.38 & 0.38 & 0.42 & 0.39 & 0.55 & 0.42 & 0.42 & 0.41 & $0.40 \%$ & $4.7 \%$ \\
\hline
\end{tabular}


$120,000 \mathrm{~h}^{-1}$ ), orange data points are from the many-to-many experiment (SGHSV 120,000 $\mathrm{h}^{-1}$ ). The two experiments, gave similar methane conversions, with the RSD in the many-tomany (orange) data being only slightly higher. Even so, both data sets show essentially the same activity level and deactivation trend over time $(\mathrm{ToS}=170-270 \mathrm{~h})$.

\section{Conclusions}

Two series of catalysts have been prepared; $\mathrm{Pt} / \mathrm{Al}_{2} \mathrm{O}_{3}$ for WGS and $\mathrm{Rh} / \mathrm{Al}_{2} \mathrm{O}_{3}$ for $\mathrm{SMR}$ reactions, whilst a further commercial LTS catalyst was used for WGS. For both reactions, two types of experiments were performed to determine the standard deviation with regard to reproducibility. The first experiments are one-tomany, referring to one catalyst batch (prepared or commercial) tested in many reactors. The other experiment is many-to-many, in which a series of eight batches of the same catalyst were prepared and all tested for their performance.

ICP analysis indicated that loadings of both $\mathrm{Pt}$ and Rh were performed accurately through incipient wetness impregnation using the synthesis robot. In addition, $\mathrm{CO}$ chemisorption experiments of the $\mathrm{Pt}$ catalysts suggest equal active metal distribution on the alumina support. The reproducibility of the WGS and SMR reaction were assessed with both one-to-many and many-to-many experiments. The calculated RSD are all found to be $6 \%$ or lower (Table 3 ) and activity trends over time between experiments are almost identical. The performance data collected in this study represents approximately 1000 hours per sample, which under conventional single reactor test protocols would have taken well over a year to achieve. This, along with the high accuracy and reproducibility shown in this study, clearly show that high throughput tools are extremely valuable for catalyst development.

\section{Acknowledgement}

The authors would like to thank Yi Zhou for his research contributions to the characterizations of the catalysts and discussions on the water-gas shift reaction. This work has been made possible with financial support from HySA/Catalysis Centre of Competence (www.hysacatalysis.uct.ac.za) and the Department of Science and Technology, South Africa.

\section{References}

[1] Acar, C., Dincer, I. (2015). Impact Assessment and Efficiency Evaluation of Hydrogen Production Methods. International Journal of Energy Research, 39:1757-1768 .

[2] Farrauto, R., Hwang, S., Shore, L., Ruettinger, W., Lampert, J., Giroux, T., Liu, Y., Ilinich, O. (2003). New Material Needs for Hydrocarbon Fuel Processing: Generating Hydrogen for the PEM Fuel Cell. Annual Reviews of Materials Research, 33: 1-27.

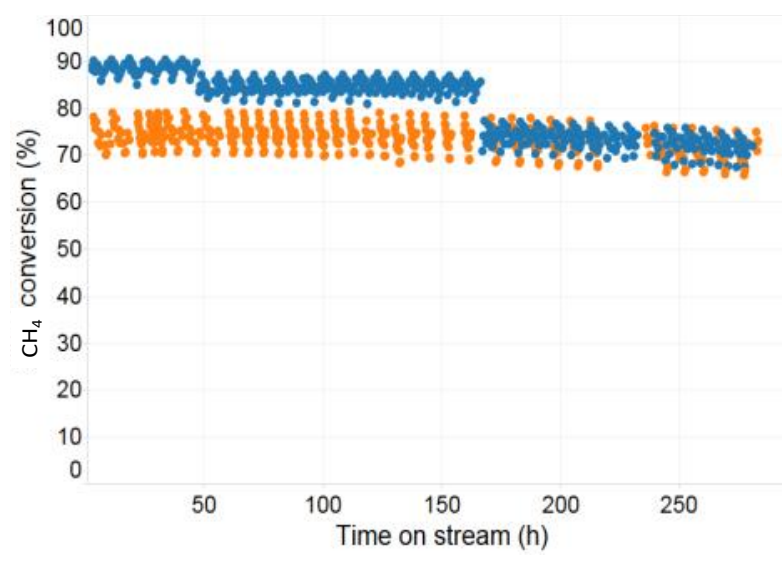

Figure 5. Steam methane reforming activities for one-to-many (blue data points) and manyto-many experiment (orange data points) (Experimental conditions: $700{ }^{\circ} \mathrm{C}, 1$ barg, $\mathrm{S} / \mathrm{C}=3$; Blue data points (one-to-many) at SGHSV 50,000 h-1 (ToS = 0-50 h), 75,000 h-1 $(\mathrm{ToS}=50-170 \mathrm{~h}), \quad 120,000 \quad \mathrm{~h}^{-1}$ (ToS $=170 \mathrm{~h}$-end); Orange data points at SGHSV 120,000 h-1)

Table 3. Comparison of RSD in activity screening

\begin{tabular}{lcclcc}
\hline & \multicolumn{2}{c}{ WGS } & & \multicolumn{2}{c}{ SMR } \\
\cline { 2 - 3 } \cline { 5 - 6 } & Conversion $^{\mathrm{a}}$ & RSD & & Conversion $^{\mathrm{b}}$ & RSD \\
\hline One-to-many & $38.8 \% \pm 2.4$ & $6.3 \%$ & & $73.2 \% \pm 2.0$ & $2.7 \%$ \\
Many-to-many & $53.2 \% \pm 2.2$ & $4.1 \%$ & & $72.5 \% \pm 2.8$ & $3.8 \%$ \\
\hline
\end{tabular}

a Average $\mathrm{CO}$ conversion \pm (absolute) standard deviation

b Average $\mathrm{CH}_{4}$ conversion \pm (absolute) standard deviation 
[3] Kobayashi, T., Ueda, A., Yamada, Y., Shioyama, H. (2004). A Combinatorial Study on Catalytic Synergism in Supported Metal Catalysts for Fuel Cell Technology. Applied Surface Science, 223: 102-108.

[4] Dincer, I., Zamfirescu, C. (2012). Sustainable Hydrogen Production Options and the Role of IAHE. International Journal of Energy Research, 37: 16266-16286.

[5] Kolb, G. (2008). Fuel Processing for Fuel Cells, Weinheim, Germany, WILEY-VCH Verlag $\mathrm{GmbH} \& \mathrm{Co}$.

[6] Ercolino, G., Ashraf, M.A., Specchia, V., Specchia, S. (2015). Performance Evaluation and Comparison of Fuel Processors Integrated with PEM Fuel Cell Based on Steam or Autothermal Reforming and on CO Preferential Oxidation or Selective Methanation. Applied Energy, 143: 138-153.
[7] Maier, W.F., Stöwe, K., Sieg, S. (2007). Combinatorial and High-Throughput Material Science. Angewandte Chemie International Edition, 46: 6016-6067.

[8] Farrusseng, D. (2008). High-Throughput Heterogeneous Catalysis. Surface Science Reports, 63: 487-513.

[9] Potyrailo, R., Rajan, K., Stöwe, K., Takeuchi, I., Chisholm, B., Lam, H. (2011). Combinatorial and High-Throughput Screening of Materials Libraries: Review of State of the Art. ACS Combinatorial Science, 13: 579-633.

[10] Maclean, D., Baldwin, J.J., Ivanov, V.T., Kato, Y., Shaw, A., Schneider, P. (1999). Glossary of Terms used in Combinatorial Chemistry, International Union of Pure and Applied Chemistry, 71: 2349-2365. 